\title{
Grafite: a consciência através das palavras
}

\section{Graffite: consciousness through the words}

\author{
Bruna Gabriela Corrêa Vicente ${ }^{1}$
}

Recebido em: 30/08/2017

Aprovado em: 12/07/2019

Publicado em: 30/07/2019

Resumo: $O$ presente artigo busca desvelar sentidos, bem como questionar representações constituídas em torno da arte urbana a fim de defender alternativas comprometidas com a humanização das classes subalternizadas. Fundamentou-se teórico-metodologicamente na Análise de Discurso Crítica (Fairclough, 2001). O corpus analítico se compôs de uma matéria de capa da Revista do Correio, ano 12, número 613, parte adjacente do jornal Correio Brasiliense do dia 12 de Fevereiro de 2017. A análise feita nos remete a uma compreensão político-ideológica, que revela conflitos da luta do grafite na busca por lugar nas artes e na sociedade.

Palavras chave: Discurso; Grafite; Cultura.

Abstract: This article seeks to reveal meanings, as well as to question representations constituted around urban art in order to defend alternatives committed to the humanization of the subalternized classes. It was theoretically-methodologically based on Critical Discourse Analysis (Fairclough, 2001). The analytical corpus was composed of a cover Revista do Correio Year 12, number 613, adjacent part of the newspaper Correio Brasiliense Of February 12, 2017. The analysis made us refer to a politicalideological understanding, which reveals conflicts of the struggle of graphite in the search for place in the arts and society.

Keywords: Discourse; Graffite; Culture.

1. Graduação em Letras. Mestranda do Programa de Pós-Graduação Interdisciplinar em Educação, Linguagem e Tecnologias. Pesquisadora do Grupo ARGUS (CNPq). Colaboradora do projeto: Ensino, Educação Estética e processos de letramento. ORCID: 0000-0003-0142-5476 Email: bruna-gab@hotmail.com 


\section{INTRODUÇÃO}

Bebida é água.

Comida é pasto.

Você tem sede de que?

Você tem fome de que?

A gente não quer só comida,

A gente quer comida, diversão e arte.

(Arnaldo Antunes/ Marcelo Fromer/ Sérgio Britto)

"Comida" (Arnaldo Antunes, Marcelo Fromer, Sérgio Britto,1992) nos remete aos anseios do ser humano, anseios que não se resumem apenas ao sustento do corpo, mas, anseios subjetivos, psicológicos, espirituais. Não queremos só comida e água, queremos algo mais, queremos criar e usufruir, " $A$ gente quer comida, diversão e arte". A música critica a sociedade moderna que se tornou estática e falida em sua principal característica humana, sua forma ou condição inata de produção e recepção da cultura. Sabemos que a necessidade de produção e recepção da cultura é inerente do ser humano, além de ser uma das maiores formas de consolidação da identidade da tribo que a produz e esse aspecto, além de caracterizá-la, a diferencia das outras, e é esta a crítica que se percebe na música, pois a subjetividade do sujeito está sendo deixada como segundo plano.

As cidades se tratam de espaços de coexistências simbólicas significativas. Contra fluxo dos planejamentos urbanos e misturados às outras intervenções nas cidades contemporâneas, os grafites vêm despertando atenção e provocando polêmicas nas políticas governamentais, no circuito das artes, nos estudos acadêmicos. Arte para uns, poluição visual para outros, não podemos negar que os grafites já fazem parte da paisagem, do dia-a-dia dos sujeitos. Ainda que de um modo geral essas intervenções sejam transgressoras, os grafites apresentam técnicas e políticas diferenciadas de acordo com o propósito de cada sujeito ou tribo.

O estudo dessas manifestações, entretanto, exige certo cuidado e nos impõe certas restrições, devido a essas intervenções estarem nas paisagens 
da cidade, são difíceis de serem precisadas, tanto no que tange às suas datas, conteúdos ideológicos e autoria, contravenções raras vezes são assinadas. Os grafites nem sempre são entendidos enquanto expressão do sujeito artista, ainda mais quando a intervenção se dá em espaços públicos especialmente aqueles de acesso a todos, espaços que muitas das vezes, são escolhidos justamente por sua visibilidade. É histórico este silenciamento das artes urbanas, como ocorreu em São Paulo, no governo Jânio Quadros, quando a prefeitura, em nome da "limpeza pública", ordenava que se apagassem os desenhos. Atualmente também em São Paulo, capital do grafite brasileiro, o atual prefeito João Dória com seu projeto higienista "Cidade Linda" deliberou que apagassem o maior mural de arte urbana da América Latina. O mural ficava localizado na Avenida 23 de maio e foi inaugurado no início de 2015, com 15 mil metros e diversos grafites de mais de 200 artistas, entre eles: Os Gêmeos, Nina Pandolfo, Nunca, Finok e Zefix. Guilherme Valiengo, diretor do documentário Cidade Cinza (2013), afirma que isso sempre ocorreu na cidade. "Você pode até patrocinar alguns grafiteiros para pintar em regiões específicas, como ocorre nos túneis da avenida Paulista, ou na radial Leste. Só que a transgressão está no DNA da coisa", diz. "E quanto aos milhares de grafiteiros e pichadores que existem e não foram chamados para participar? Eles vão pichar onde tiverem vontade, não adianta querer enquadrar". Os grafiteiros se (re)apropriam da cidade como lugar da cultura, não só a cultura dos dominantes, mas do povo, dos que nela vivem e trabalham. Desta forma, se percebe que os grafites de ontem não são os de hoje, os de hoje não serão os de amanhã. Os grafites serão sempre os do aqui e do agora.

\section{Grafites e cultura}

O grafite, manifestação artística urbana que, nos últimos quarenta anos, espalhou-se pelas grandes metrópoles do mundo. Tornou-se um elemento visual cotidiano para os habitantes dessas grandes cidades. Sua presença nos mais variados espaços coletivos e suportes tem sido alvo de grandes tensões sociais, criando nuances das mais variadas deste fenômeno artístico. Manifestação artística urbana com vários estilos e vertentes, o grafite possui 
ampla abrangência e pode ocorrer em vários locais ao mesmo tempo: é uma cultura disseminada que está presente em todo o globo.

Canclini (2003, p. 339) define o grafite como "[...] prática híbrida, efêmera e marginalizada, um modo de assumir novas relações entre o privado e o público, entre a vida cotidiana e a política". com referências transgressoras, sexuais e políticas, os grafites surgem como expressões do modo de viver e pensar de grupos que não estão inseridos em circuitos políticos, comerciais e midiáticos. Com traços espontâneos e manuais, o grafite afirma o território, abala concepções de propriedade, bens materiais e simbólicos.

Nas diversas formas em que os grafites surgem, "eles fundem palavras, imagens, signos, mensagens e ideologias em um estilo descontínuo, fragmentado e heteróclito: uma síntese da topografia urbana" (CANCLINI, 2003, p. 339). Toda essa complexidade inerente do grafite que Canclini (2003) aponta demonstra que as fronteiras entre o que se escreve nos muros e o que se vê nas galerias de arte são tênues. $O$ grafite possui essência efêmera e marginal, estabelece relações entre privado e público, vida cotidiana e política. Dessa maneira, o grafite pode ser entendido como forma de expressão popular que critica a ordem social imposta.

Em Nova York, como aponta Veneroso e Melendi (2009), o grafite surgiu como forma de resistência, praticado por indivíduos pertencentes a duas expressivas e específicas minorias étnicas: os negros e os porto-riquenhos. Manifestação característica dos guetos do Bronx e do Brooklyn, com suas próprias normas, leis e propósitos políticos. Expressão dos oprimidos que não tendo onde lugar de fala, se expressavam nas ruas, inicialmente "artistas como Taki 183, Julio 20, Cat 161 e Cornbread pintavam seus nomes nos muros e nas estações de metrô ao redor de Manhattan" (GANZ, 2010, p. 8). Usavam símbolos que tinham como objetivo subverter o sistema comum dos nomes. Segundo Gari (1995), o Grafite deriva da cultura hip-hop emergente no período, a qual correspondia à expressão visual de um movimento composto, igualmente, pela vertente musical djing e mcing e breakdance.

A profusão de novos grafites em NY inspirou os grafiteiros a darem novas formas e destaques a suas obras, as tags se tornaram maiores e começam a aparecer as primeiras pieces (abreviação de Masterpieces, "obra- 
prima"). No princípio, os artistas utilizavam os trens por estes fazerem o trajeto por toda a cidade, mas em meados de 1980 as autoridades da cidade tomaram medidas judiciais para proteger sua propriedade dos grafiteiros. Na medida em que os grafiteiros nova-iorquinos visitavam outros lugares, o fenômeno se espalhou e logo os trens se tornaram alvo na Europa, ao mesmo tempo Amsterdam e Antuérpia recebiam exposições de arte em grafite, todavia, as particularidades locais são relevantes, em alguns casos, para demonstrar como os indivíduos localmente se apropriam e recriam idiomas culturais transnacionais.

Na década de 1980, no Brasil, ocorre uma reestruturação forçada na prática da grafitagem devido à ditadura militar, a atividade era tida como "ilegal e subversiva" (GITAHY, 1999, p. 13). O grafite assume expressiva fonte de opinião pública, ligada à literatura e às canções de protesto.

O grafite, pois, junto à denuncia e aos anseios de uma novas ordens sociais, também possui opções para ser compreendido como arte e literatura, como expressão e comunicação, enfim, como realidades sociais e utopias urbanas, com a privilegiada condição de tratar-se de uma escritura criada coletivamente (SILVA, 1987, p.17).

Conforme aponta Melendi (2003), o grafite se estabelece como voz que sai das margens da república democrática, um produto residual dos longos anos da ditadura e do descaso do estado neoliberal.

Para Martin-Barbero (1997), trata-se do "espaço da mestiçagem da iconografia popular". A voz que antes pertencia apenas aos grandes centros agora também pertence a margem, o grafite sai da ilegalidade dos sanitários e espalha sua mensagem desbocada e transgressora pelos muros da cidade. A cidade se abre à poética e a poética popular se reveste de crítica política. Diversas manifestações se encontram e se fundem, registrando protestos pelos espaços urbanos, a década de 1980 foi marcada por movimentos urbanos que buscavam mudanças sociais, as quais foram determinantes para a afirmação dessa arte de rua.

Para Certeau (1994), as estruturas de resistência são as mesmas, tratam-se de processos desiguais que propagam o confronto de ideias, a 
resistência. Canclini (2003) afirma que o grafite é uma escrita territorial dos locais urbanos, que consolida a presença de sujeitos marginalizados, luta e a apropriação do espaço através de ideias e os modos de ser e pensar de seus produtores.

O Grafite tem como prerrogativa um caráter contestatório da arte, seus artistas optam por locais públicos e com grande concentração de passantes para a criação de sua arte. Diante da existência dessas obras na cidade, Barthes afirma que:

A cidade é um discurso, e esse discurso é verdadeiramente uma linguagem: a cidade fala aos seus habitantes, nós falamos à nossa cidade, a cidade onde nos encontramos simplesmente quando a habitamos, a percorremos, a olhamos. (BARTHES, 2001, p. 224)

Logo podemos pensar o grafite para além da lógica da produção de sentidos, tomando-o em sua materialidade mais concreta, enquanto inscrição ou traço que marca a intervenção de um "alguém" que pode ser qualquer um e todos, evidenciando a dimensão política da subjetividade.

A prática artística estendida ao ambiente urbano representa a possibilidade de mudanças na relação dos indivíduos com a cidade, já que ao "invadir" esses espaços, propõe novas formas de enxergá-la, de significá-la e de ressignificá-la. A ação artística estendida ao cotidiano realiza construções de sentidos que transformam a paisagem urbana e propõe novas leituras da realidade. Para Michel de Certeau (2014), a cidade pode ser pensada a partir das rotas dos planejadores, dos discursos de poder de quem as gerencia, mas também pode ser pensada como um texto que se escreve constantemente pelas práticas dos usuários. O território urbano pode ser lido a partir das vivências, encontros, experiências e narrativas que proporciona, apesar dos discursos normativos e funcionalistas que o orientam.

Se acompanharmos a história da arte e da humanidade, perceberemos que a necessidade de expressão pela arte visual esteve presente desde os tempos mais remotos. Em termos de produção artística, os desenhos nas paredes das cavernas são as manifestações mais antigas feitas pelo homem, que apresentavam uma linguagem simbólica particular. Com 
efeito, experiências estéticas foram produzidas, vivenciadas e discutidas das formas mais diversas, refletindo sobre as realidades impostas ao humano, em diferentes momentos do processo civilizatório. A relação do homem com a linguagem e as transformações por que ela passou mostra-se, portanto, como um oportuno tema para o início de nossas reflexões.

Nesta realidade, a fluidez da sociedade - comunicação e deslocamento -permite que surjam construtos sociais elaborados a partir de referências múltiplas. Elementos culturais e fatos históricos podem ser ressignificados em novos contextos, sendo incorporados com outra configuração. Diante disso, é vital considerar a construção de pertencimentos calcados em identidades culturais como de grande importância para a compreensão dos fenômenos culturais no final do século XX e início do XXI.

$E$ é nesse estatuto sociocultural multi e controverso que a arte se encontra, desafiada pelo papel fundamental que ocupa na sociedade, ou seja, na formação do sujeito complexo contemporâneo, com o fim de capacitá-lo a exercer sua cidadania com responsabilidade social e comprometimento ético, sem esquecer-se das prerrogativas da autonomia e da identidade.

De acordo com Hernández (2000), a Arte é uma prática social, uma forma de conhecer e relacionar-se com o mundo. À luz da Cultura Visual, a Arte é compreendida como produção social e cultural do sujeito e de sua coletividade, com características inerentes aos períodos em que essas produções artísticas foram geradas.

Nesse sentido, podemos pensar a arte urbana como prática crítica capaz de propor resistência a modelos funcionalistas de uso da cidade, já que evidencia uma construção do território urbano por parte daqueles que dele fazem uso, ao mesmo tempo em que questiona o limite das práticas institucionalizadas das artes.Tais práticas, ao deslocarem sua atuação das instituições de produção, distribuição e exposição tradicionais (museu, galeria, academia, mídia), e ao adentrarem no território citadino provocariam novos usos desses espaços e fissuras nos sistema institucionalizados das artes. Interessa-nos destacar a relação estabelecida entre a literatura e a arte urbana, bem como aspectos característicos de um trabalho experimental da poesia 
contemporânea que utiliza os espaços da cidade como suporte, num exercício de deslocamento das mensagens para além dos livros.

Silva (1987) aborda o grafite como um processo de comunicação urbana com a população e com seus pares e que possui características específicas. Para o autor, a América Latina representa o terceiro grande momento do grafite contemporâneo, precedido por Paris em 1968 e Nova York na década de 1970.

Atualmente existem as mais variadas vertentes do grafite, e elas se misturam em grandes cidades da América Latina: da iconografia popular à criação de grandes murais, de mensagens de cunho e críticas sociais a movimentos que aproximam o grafite, ainda mais, das artes plásticas. Nota-se que a intencionalidade política destes grafites não propõe uma tomada de poder, mas desejo de participação social e voz.

O grafite, juntamente com as manifestações sociais e políticas e os monumentos são linguagens que representam forças que operam na cidade. De acordo com Canclini (2003, p. 356), os monumentos são, em sua maioria, "obras em que o poder político exalta pessoas e acontecimentos ligados ao Estado". Enquanto os grafites expressam a crítica e a insatisfação popular à ordem imposta:

Assim, a trocas entre os monumentos e as mensagens publicitárias e políticas situa como organização da memória e da ordem visual, ou seja, uma forma de controle da estética do meio urbano, uma imposição da arte feita pelo Estado, a exemplo: O Bandeirante, monumento no centro da cidade de Goiânia.

Olhar esteticamente os grafites amplia as possibilidades de relação do sujeito com a cidade, com os objetos, com os outros e consigo mesmo, visto que os sujeitos, observando-os por outro ângulo e estabelecendo outras conexões, criam para si novas formas de ver o mundo, compondo outras tramas de existência, novos valores e novas sensibilidades, ressignificando-se neste processo. Logo, temos que pensar que nem sempre os grafites são feitos por aqueles se sentem excluídos da cidade. As razões e os sujeitos são diversos, como já bem mostram as mensagens, ações e imagens. Muitos grafiteiros estudam arte e agem cientes do que e para quem estão produzindo, tendo em vista um pensamento ideológico político ou não. 
Rancière (2009) sugere o entrelaçamento entre a estética e a política evidenciando que as 'formas de fazer' da arte influenciam as 'formas de fazer' na sociedade através de sua linguagem particular que atinge de maneira ampliada os diversos sentidos. De acordo com Vigotski (1993), podemos pensar que se trata de relações estéticas que possibilitam produzir outros sentidos para o que é visto e reconhecido, assim como reconstruir o olhar sobre o mundo.

Sendo assim podemos afirmar que grafite enquanto artefato da pós modernidade rompe com os espaços de exposição tradicional, como museus e galerias, para criar diálogos com lugares e recolocar o campo da criação artística entre os objetos do cotidiano. Em relação a isso Martinon versa:

De fato e por direito, tudo aquilo que pode ser entendido como uma organização, como uma regulação simbólica da vida social pertence à cultura, sendo esta a maneira pela qual se agenciam num mesmo todo elementos tão diversos quanto a arte e a arquitetura, com ou sem arquiteto, as posturas nas práticas do parto, micção, defecação, os rituais de casamento, morte, a escritura ou o arco e flecha. Todos esses traços culturais formam um conjunto de modelos diferentes de organização da vida social, de acordo com a sociedade que a etnologia descreve ou mesmo de acordo com os grupos estudados dentro de uma mesma sociedade. Todas as vezes que os aspectos, os segmentos da vida social puderem ser discernidos e compreendidos a partir de uma coerência simbólica - aquilo que seria chamado de modelo de comportamento pela sociologia americana, - tratar-se-á aí de cultura (MARTINON apud SANTAELLA, 2003 p. 37)

Assim, ao ocupar o espaço urbano, o grafite abre novas possibilidades de percepção da cidade e provoca a ressignificação do olhar, ampliando as relações do ser humano com a realidade, modificando essas relações e os próprios sujeitos, rompendo com a concepção clássica de estética. Os grafiteiros ressignificam a cidade, dão ela caráter de criação de novos significados, fazem da cidade espaços de diálogo. Os grafites possibilitam a percepção de uma nova configuração para a cidade, não mais vista e pensada a partir de um projeto moderno e técnico, mas fractal, participativa e ativista. 


\section{A consciência através das palavras}

A contemporaneidade está permeada por disputas ideológicas e culturais na construção da hegemonia, as quais influenciam e condicionam o imaginário social. Esta busca de espaço e consenso de determinadas ideologias torna-se fator primordial das disputas de poder, entre classes, instituições e organizações que representam a sociedade civil.

Assim, é a cultura como um todo que a cultura urbana coloca em movimento, acelerando o tráfego entre as múltiplas formas, níveis, setores, tempos e espaços. A prática artística estendida ao ambiente urbano representa a possibilidade de mudanças na relação dos indivíduos com a cidade, já que ao "invadir" esses espaços, propõe novas formas de enxergá-la, de significá-la e de ressignificá-la. A ação artística estendida ao cotidiano realiza construções de sentidos que transforma e propõe novas leituras da realidade. Para Michel de Certeau (2014), a cidade pode ser pensada a partir das rotas dos planejadores, dos discursos de poder de quem as gerencia, mas também pode ser pensada como um texto que se escreve constantemente pelas práticas dos usuários. O território urbano pode ser lido a partir das vivências, encontros, experiências e narrativas que proporciona, apesar dos discursos normativos e funcionalistas que o orientam.

A pichação e o Grafite contemporâneo no Brasil são expressões no modo de vida e pensamentos de grupos marginalizados e subalternizados. Com referências sexuais, políticas e estéticas, a pichação e o grafite não dispõem de ferramentas comerciais, políticas e midiáticas de massa para se posicionarem e a apropriação do ambiente urbano por meio de marcas de expressões culturais e de resistência à ordem, como infere Foucault:

[...] onde há uma relação de poder, há uma possibilidade de resistência. Jamais somos aprisionados pelo poder: podemos sempre modificar sua dominação em condições determinadas e segundo uma estratégia precisa. (FOUCAULT, 1985, p. 241.)

Os grafites expressam a crítica e a insatisfação popular à ordem imposta: 
Os grafites (como os cartazes e os atos políticos da oposição) expressam crítica popular à ordem imposta. Por isso são tão significativos os anúncios publicitários que ocultam os monumentos ou os contradizem, os grafites inscritos sobre uns e outros. Às vezes, a proliferação de anúncios sufoca a identidade histórica, dissolve a memória na percepção ansiosa das novidades incessantemente renovadas pela publicidade. (CANCLINI, 2012, p. 302.)

Ainda de acordo com o autor, essas disputas de poder são metáforas dos conflitos entre forças sociais, o mercado e o estado.

Por ser subversiva a arte urbana contrapõe-se às legendas políticas e de poder. Por ter um traço espontâneo e transgressor o grafite e a pichação afirmam territórios, descaracterizam a concepção de que a cidade se trata de um bem material exclusivo único e simbólico de uma parcela da sociedade.

Vale ressaltar que o grafite e a pichação enquanto atividades culturais se amalgamam com práticas sociais e originam formas específicas de engajamento:

Todo ato histórico não pode deixar de ser realizado pelo 'homem coletivo', isto é, pressupõe a conquista de uma unidade 'cultural-social' pela qual a multiplicidade de vontades desagregadas, com fins heterogêneos, solda-se conjuntamente na busca de um mesmo fim, com base numa idêntica e comum concepção do mundo. (GRAMSCI, 1999, p.398 apud MORAES, 2016)

Essas formas específicas de engajamento se reconhecem na pluralidade e na diversidade cultural ao mesmo tempo em que propõe construir projetos que abarcam uma vontade coletiva de criação de um espaço público onde se pode combinar hegemonia e pluralidade cultural.

Cabe lembrar que muitas das iniciativas governamentais no que se refere às políticas públicas decorrem de reivindicações de movimentos sociais, uma vez que a pluralidade é uma exigência para a democracia. Como versa Orlandi:

O grafitismo está inserido no nosso cotidiano como forma de arte, é a maneira que algumas pessoas acharam para expressar suas idéias recheadas de uma ideologia onde é expressa de maneira natural e sem represálias o que pensam e sentem. Os grafiteiros como são chamados buscam através dos seus desenhos mostrarem uma sociedade mais justas onde eles acreditam que seria a ideal no cotidiano de cada um deles. Esses espaços pichados e grafitados têm sido destinados a manifestações discursivas que aliam o sujeito à 
sua história e à sua língua, em uma relação de significação de si próprio, de sua identidade e desses locais, na medida em que „nas cidades grandes o movimento da grafitagem é desencadeador de um movimento de consciência que atravessa toda a população segregada [...]. (ORLANDI, 2004, p.13).

Um dos fundamentos da Análise Crítica do Discurso é avaliar o lugar/papel do discurso na constituição das identidades, relações sociais, sistemas de conhecimento, crenças, normas de comportamentos e hegemonias culturais, construindo diferentes modos de desvelar significados de: ação, representação e identificação entre os sujeitos e o mundo (FAIRCLOUGH, 1992, 2001).

A ACD se debruça, também, na estrutura da ordem do discurso, esta que não se trata de um sistema engessado, mas assim flexível dependendo do que venha a ocorrer nas interações sociais que a circundam. Neste interim procura-se então interpretar o sentido das escolhas, as ordens do discurso e as relações de poder. A ACD atende muito mais uma teoria a um método, considera o discurso como prática social em articulação com outras ações, momentos, relações e processos de poder e institucionais.

Quando uma análise é feita é examinada a articulação entre o discurso e outros contextos inter-relacionados tais como momentos da prática e estrutura social. Fairclough, defende,

O discurso como prática política estabelece, mantém, e transforma as relações de poder e as entidades coletivas (classes, blocos, comunidades, grupos) entre as quais existem relações de poder. O discurso como prática ideológica constitui, naturaliza, mantém e transforma os significados do mundo de posições diversas nas relações de poder. (FAIRCLOUGH, 2001, p. 94)

A ideologia constrói e significa a realidade em várias dimensões das "formas/sentidos" (p. 117) em relação às práticas discursivas, as contribuições para sua produção, reprodução e/ou transformação são inerentes às relações de poder e dominação estabelecidas pela classe hegemônica vigente. Fairclough, entende a ideologia como um componente essencial para a criação e manutenção das relações desiguais de poder. Portanto, um dos aspectos norteadores de suas análises é saber como a linguagem media a ideologia no 
contexto social, ou seja, é "a capacidade de ser dirigente e de fiscalizar o próprio dirigente, não apenas a capacidade de direção política, mas também de direção moral, cultural, ideológica dos que lutam por reafirmar seu lugar social" (GRUPPI, 1978, p.11). Seu posicionamento compactua com a de Thompson (2002, p.96) que versa que ideologia é o estudo "de como o significado é construído e transmitido através de formas simbólicas".

Partindo disto, a sociedade civil seria uma das esferas que designam as instituições norteadoras da difusão e elaboração das ideologias, tais como: sistema escolar, sindicatos, meios de comunicação, artístico e cultural.

\section{Desvelando os textos: a consciência através das palavras}

A linguagem midiática, hoje, se trata de uma das mais difundidas e de mais fácil acesso às jovens enquanto instituição que agrega valores sociais, culturais e linguísticos. A mídia constrói, através da linguagem, a imagem dela própria, de seu público consumidor e da relação estabelecida entre esses participantes exercendo vários papeis na sociedade, entre eles a percebemos como formadora de opinião, não apenas para construir e/ou reforçar identidades, mas também para inferir e criar estereótipos étnicos, econômicos, sociais e intelectuais, também incluem ou excluem indivíduos de determinados grupos sociais, enfatizando diferenças de sexo, raça e idade.

Os dilemas que norteiam a produção midiática se originam, sobretudo, nas questões de poder econômico. Trabalhos de Fowler, Fairclough, Gonzaga Motta entre outros, tratam da questão do poder e produção midiática e que tem como fator norteador as questões de poder que tem em seu centro a relação de dependência entre o fator econômico e a notícia. Mesmo com todas essas ambiguidades não se pode negar que a produção/ distribuição midiática tem seu papel como formadora de opinião.

Para este artigo, devido a limitação de tempo e espaço, selecionei a capa da Revista do Correio, ano 12, número 613, parte adjacente do jornal Correio Brasiliense do dia 12 de fevereiro de 2017. 
Figura 1 - Revista do Correio.

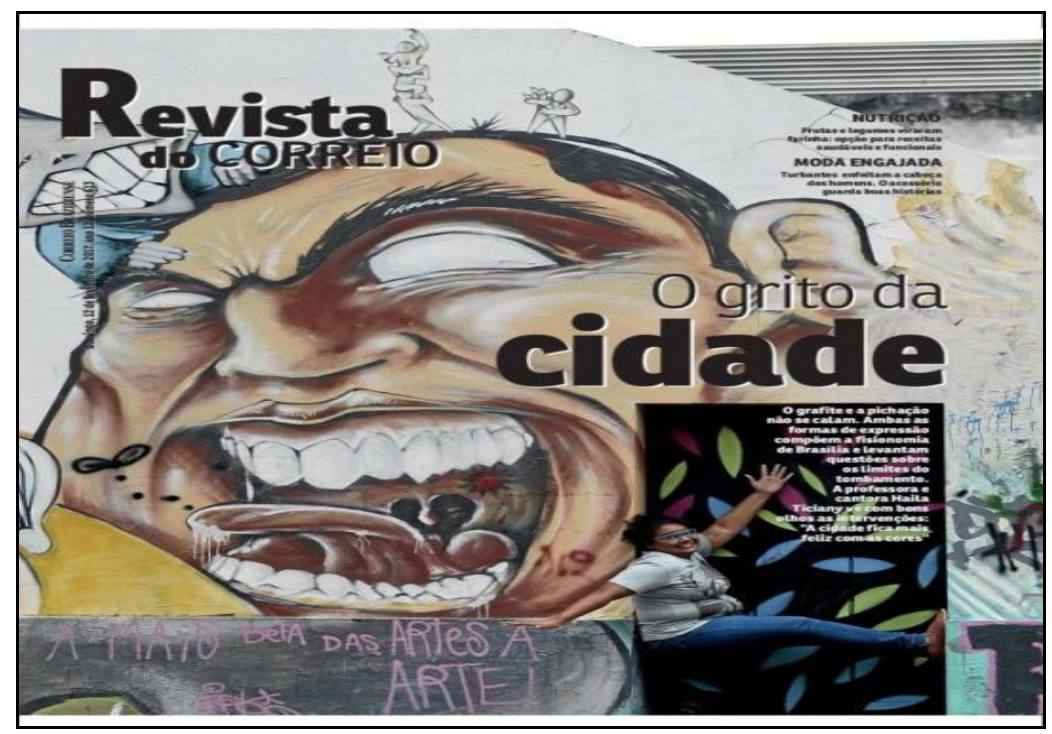

Fonte: http://www.correiobraziliense.com.br/revista-do-correio/

A capa da revista traz uma grande foto colorida, ocupando toda a página. Composta por um grafite do prefeito de São Paulo, Dória, em sua cabeça homens cinzas em referência ao ato do prefeito da cidade de São Paulo, cidade expoente do grafite no Brasil, deliberou que os muros da cidade deveriam pintados de cinza,e uma pichação "A MAIS Bela das ARTES A ARTE" (1), logo abaixo uma adolescente negra, fora dos padrões hegemônicos do que deve ser o corpo de uma mulher capa de revista e uma chamada para a matéria principal "O grafite e a pichação não se calam" (2), "Ambas as formas de expressão compõem a fisionomia de Brasília" (3) "levantam questões sobre os limites do tombamento"(4), "A professora e cantora HailaTiciany vê com bons olhos as intervenções" (5) "A cidade fica mais feliz com as cores."(6). O discurso nos exemplos dá ênfase ao caráter contestatório do ato de grafitagem e pichação, por meio de diversos recursos semióticos e linguísticos.

Intertextualidade: para Fairclough (2001), os enunciados são inerentemente intertextuais, constituídos por elementos de outros textos. No início do discurso "A MAIS Bela das ARTES A ARTE" (1), remete às Belas Artes da Renascença e como apenas algumas áreas culturais eram consideradas arte. O texto responde textos passados e, assim, ajuda na construção da história e contribui nos processos de mudança mais amplos, antecipando e tentando moldar textos subsequentes. Para Fairclough, os textos 
evidenciam os processos de transformação e reestruturação de tradições textuais e de ordens do discurso. Por meio do uso desse enunciado, a revista se aproxima do leitor, colocando-o solidário com o problema que será discutido posteriormente na matéria principal.

Coesão: nos enunciados "O grafite e a pichação não se calam" (2), "Ambas as formas de expressão compõem a fisionomia de Brasília" (3) estabelece-se a coesão por colocação (HALLIDAY; HASAN, 1976). Pode-se perceber uma relação de casualidade entre as frases.

Seleção de itens lexicais: "levantam questões sobre os limites do tombamento" (4), reforça a representação negativa do grafite e da pichação e demonstra como os espaços vividos pelos transeuntes e artistas são constituídos por meio de limites atribuídos a eles por um poder hegemônico do estado.

Metáforas Conceptuais: "O grafite e a pichação não se calam" (2), "A cidade fica mais feliz com as cores" (6), relativos ao sentido, à compreensão, à verdade e à objetividade. Uma metáfora conceptual é uma maneira convencional de conceitualizar um domínio de experiência em termos de outro, normalmente de modo inconsciente, metáfora conceptual é assim chamada pois expressa um conceito e é de abordagem cognitiva por que propõe que as metáforas são construções mentais fundamentais para o entendimento da linguagem.

Semiose (imagens visuais): nota-se uma economia linguística ao fazer uso da imagem do grafite. Como dito anteriormente, o prefeito da cidade de São Paulo João Dória com o projeto "São Paulo Cidade Linda" propõe apagar as pichações e grafites característicos da cidade, entre eles o maior painel grafitado da América latina. $O$ grafite demonstra a imagem de um ser exaltado com olhos cinzas, fazendo referência ao projeto e uma crítica à impossibilidade do prefeito de enxergar cores. Nesse sentido, podemos pensar a arte urbana como prática crítica capaz de propor resistência a modelos funcionalistas de uso da cidade, já que evidencia uma construção do território urbano por parte daqueles que dele fazem uso, ao mesmo tempo em que questiona o limite das práticas institucionalizadas das artes. Tais práticas, ao deslocarem sua atuação das instituições de produção, distribuição e exposição tradicionais (museu, 
galeria, academia, mídia), e ao adentrarem no espaço provocam novos usos desses espaços e fissuras no sistema institucionalizado hegemônico das artes.

Identidade: O grafite e a pichação são mais do que apenas imagens e cores, são mensagens com significados profundos e que carregam uma carga cultura, cultural e ideológica de toda uma classe marginalizada e subalternizada que não tem voz ativa nas esferas de poder hegemônicas. Ao experimentarem os muros da cidade, se apropriarem do espaço público estas imagens ressignificam todo um espaço, que antes não pertencia a estes sujeitos. A identidade é estabelecida, socialmente, pelas diferenças e igualdades (Ciampa 1994), ou seja, diferenciando e igualando um indivíduo ao outro, a partir de 8 atributos que se determinam a partir de grupos sociais em que o sujeito social está inserido. Sendo assim, o conhecimento do sujeito enquanto indivíduo é feito pelo reconhecimento recíproco do outro, no qual se identifica por meio da esfera social na qual está permeada de sua cultura, tradições, normas, comportamentos e interesses. A questão da identidade está sendo extensamente discutida na teoria social. Em essência, o argumento é o seguinte: as velhas identidades, que por tanto tempo estabilizaram o mundo social, estão em declínio, fazendo surgir novas identidades e fragmentando o indivíduo moderno, até aqui visto como um sujeito unificado. As identidades sociais são estabelecidas por meio de práticas discursivas, é a partir da presença do outro que o sujeito molda seu discurso, o sujeito torna-se consciente de si no momento em que se vê refletido no outro. Cada identidade espelha outra, construindo, assim, uma liga de representações em que o espelho, da mesma, constrói as relações sociais conservando-as e/ou transformando-as. Hall (2006), em seus postulados versa sobre a existência de três concepções de identidade que norteiam suas discussões teóricas: uma concepção essencialista (sujeito do lluminismo), concepção formada a partir da interação entre o sujeito e a sociedade (sujeito sociológico) e uma concepção pós-estruturalista, do sujeito volátil, sem uma identidade fixa (sujeito pósmoderno). Desta feita, a partir do reconhecimento de que a identidade é constituída pela interação social, isto é, pela sua prática, no modo de agir, pensar, fazer, trabalhar, sentir, não mais no sentido de substantivo e sim de verbo, se estabelece uma segunda noção de identidade a qual é medida 
através da ação, sendo assim, quando a identidade é definida ou atribuída se faz uma representação da identidade, um produto acabado.

A mulher negra, fora dos padrões hegemônicos de beleza: existem representações anteriores à construção de identidades, como a da mulher, mãe, família, assim sendo, na medida em que essas identificações vão sendo feitas as normas de conduta dos grupos e seus comportamentos vão adotando formas e caracterizando as semelhanças entre os sujeitos inseridos na esfera social. Ao optarem pela imagem de uma mulher negra a revista reforça estereótipos de que quem faz grafite ou picha são apenas jovens negros, ao vincular um ato transgressor a esta imagem, para Ciampa (1994), por um lado é a implicação das relações entre os sujeitos, por outro é a condição prévia para que essas analogias se constituam daí se pressupõe os estereótipos, ritos, normas de conduta, formações cristalizadas. Portanto, o objeto de representação (o referente), e sua representação (nomeação), tornam-se fenômenos sociais e linguísticos.

Quando interagimos com o mundo em um determinado contexto social, representamos papeis sociais e estabelecemos identidades. Proveniente disso surgem os significados quando empregamos a linguagem e por meio da análise linguística podemos ter um olhar para o texto como representação. A análise textual, no que concerne a estrutura linguística e seus processos, traz ao nível da consciência padrões identitários e ideológicos codificados no discurso, que estão subjacentes à mensagem, para que o leitor aceite a mensagem de forma natural.

\section{CONSIDERAÇÕES FINAIS}

A análise feita nos remete a uma compreensão político-ideológica que revela conflitos da luta do grafite por um lugar nas artes e na sociedade, como, também, aspectos da desigualdade social, esses marcados textualmente e imageticamente.

Perceber a mensagem destes grupos enquanto processo cumulativo e contínuo de avanços das classes subalternizadas e marginalizadas, demonstra a capacidade diretiva desses grupos na busca por atingir mudanças das 
condições sociais desiguais vivenciadas por eles e por uma grande parcela de sujeitos sociais.

Assim, torna-se necessária a participação da sociedade civil e de segmentos reivindicantes na busca da pluralidade hegemônica. Ao tentar desnaturalizar, por meio do evento discursivo, os princípios ideológicos hegemônicos os grafiteiros e pichadores usam da habilidade de agir criativamente, assim como defende a perspectiva gramsciniana que vê a luta pela reestruturação dessas práticas contra-hegemônicas como uma forma de conquista e luta, para consequentemente ver os efeitos na ação discursiva.

Portanto, conclui-se que a linguagem/discurso conscientiza, constrói e também manipula identidades, através das estruturas sociais e suas ideologias, aqui o estudo linguístico desempenhou não apenas um caráter de análise estrutural, mas, também sociológico, a fim de mostrar como a realidade é ideologicamente representada no sentido da construção de significados a partir da modelação das relações sociais. Desconstruir estes discursos tem sua relevância, pois a partir disto serão construídos novos discursos que contemplem a realidade da vida destes sujeitos.

O presente artigo buscou desvelar sentidos no que se refere a vida social bem como questionar hegemonias constituídas em torno da arte urbana e defender alternativas comprometidas com a humanização das classes subalternizadas.

\section{REFERÊNCIAS}

BARTHES, Roland. Semiologia e urbanismo. In: A aventura semiológica. São Paulo: Martins Fontes, 2001. p. 224..

CANCLINI, N. G. Culturas híbridas: estratégias para entrar e sair da modernidade. 4 ed. São Paulo: EdUSP, 2003. Figura 7: http://www.correiobraziliense.com.br/revista-do-correio/ Acesso em: 13 de agosto de 2017.

CERTEAU, M. A invenção do cotidiano: 1. artes de fazer. Trad. Ephraim Ferreira Alves. Petrópolis, RJ: Vozes, 1994. 
CIAMPA, A, C. Identidade. In: movimento. São Paulo: Editora Brasiliense, 1994.

Psicologia social: o homem em

FAIRCLOUGH, N. Discurso e Mudança social. Brasília: Editora Universidade de Brasília, 1992, 2001.

FOUCAULT, Michel. Microfísica do Poder. 5 ed. Rio de Janeiro: Graal, 1985.

GANZ, Nicholas. O mundo do grafite: arte urbana dos cinco continentes. São Paulo: Martins Fontes, 2010.

GARI, J. La conversación mural: ensayo para una lectura del graffiti. Madri, Fundesco. 1995

GITAHY, Celso [et al] Grafiti na cidade de São Paulo e sua vertente no Brasil: estéticas e estilos. São Paulo: LABI-USP, 1999.

GRUPPI, L. 1978. O conceito de hegemonia em Gramsci. Rio de Janeiro: Graal. LACLAU, E. 1993. Discourse. In: GODDIN, R.; PETTIT, P. (orgs.). The blackwell companion to political philosophy. Oxford: Blackwell.

HALLIDAY, M. A. M. Explorations in the Functions of Language. London: Edward Arnold, 1973.

HALLIDAY, M; HASAN, R. Cohesion in English. New York: Longman. 1976

HALL, S. A identidade cultural na pós-modernidade. 11a. ed. Rio de Janeiro: DP \& A. 2006

HERNÁNDEZ, F. Cultura visual, mudança educativa e projeto de trabalho. Porto Alegre: Artmed, 2000.

MARTÍN-BARBERO, Jesús. Dos Meios às Mediações: comunicação, cultura e hegemonia. 2. Ed. Rio de Janeiro: Editora da UFRJ, 2001.

MELENDI, Maria Angélica. Imagens e Palavras. In ALMEIDA, Maria Inês de (org). Para que serve a escrita? São Paulo: EDUC, 2003.

MORAES, D. Crítica da mídia e hegemonia cultural. Rio de Janeiro: Mauad e Faperj. 2016.

ORLANDI, E. Cidade dos Sentidos. Campinas: Pontes. 2004.

RANCIÈRE, J. A partilha do sensível. 2. Ed. São Paulo: Editora 34, 2009.

SANTAELLA, L. Culturas e artes do pós-humano. São Paulo: Editora Paulus. 2003. Fichamento online. Disponível em:

http://webcache.googleusercontent.com/search?q=cache:LWamo4vXbwwJ:cult 
uradigital.br/artedocibridismo/fichamentos/culturas-e-artes-do-poshumano/\&hl=pt-BR\&gl=br\&strip=1\&vwsrc=0. Acesso em julho de 2019.

SILVA, A. Punto de vista ciudadano; focalización visual y puesta en escena del graffiti. Bogotá: Publicaciones Del Instituto Caro Y Cuervo, 1987.

THOMPSON, John. B. Ideologia e cultura moderna: Teoria social crítica na era dos meios de comunicação de massa. 6 ed., Petrópolis: Vozes, 2002.

VENEROSO, M; MELENDI, M (org). Diálogos entre linguagens: artes plásticas, cinema, artes cênicas. Belo Horizonte: Editora C/Arte, 2009

Vigotski, L. S.. La imaginación y el arte en la infancia. Madrid: Akal, 1993.

\section{Como citar este artigo (ABNT)}

VICENTE, B.G.C. Grafite: a consciência através das palavras. SELL, Uberaba, MG, v. X, n. X, p. XXX-XXX, 2019. Disponível em: <inserir link de acesso>. Acesso em: inserir dia, mês e ano de acesso. DOI: inserir link do DOI.

Como citar este artigo (APA)

Vicente, B.G.C (2019). Grafite: a consciência através das palavras. SELL, $X(X)$, XXX-XXX. Recuperado em: inserir dia, mês e ano de acesso de inserir link de acesso. DOI: inserir link do DOI. 